\title{
Pathological skeletal remains from ancient Egypt: the earliest case of diabetes mellitus?
}

\author{
TL Dupras*, LJ Williams, H Willems, C Peeters
}

\section{Introduction}

The first accurate description of diabetes mellitus, attributed to Aretaeus of Cappadocia, appeared in ancient historical sources ca. $100 \mathrm{AD}$, though many credit the Ebers papyrus as containing the earliest medical reference to the disease (see Table 1 for milestones in the history of diabetes).${ }^{1-3}$ The Ebers papyrus, dated to approximately $1530 \mathrm{BC}$, is one of the oldest Egyptian medical documents and, although it contains over 700 magical spells and medical remedies, it also contains phrasing that mentions a particular symptom indicative of diabetes mellitus. ${ }^{3-5}$ The phrases 'to eliminate urine which is too plentiful' [EB 274] and 'to put the urine in order' [EB 266] may be translated as referring to polyuria, a classic symptom of diabetes mellitus. The Ebers papyrus also refers to "correcting urine of excess' [EB264], which may be a more likely reference to polyuria due to diabetes. ${ }^{3}$ Parallels to this description are also found in the later dated (18th Dynasty, ca. 1479 BC) Hearst papyrus [H63]. ${ }^{4}$

One problem in tracing the history of diabetes mellitus is that there are no skeletal or soft tissue characteristics exclusive to diagnosis in the archaeological record; therefore, paleopathologists have relied on textual evidence to trace the appearance of this disease. If it is possible to identify diabetes mellitus in skeletal remains, it can only be achieved through differential diagnosis so that all potential diseases are considered. Due to the pathogenic complexity of diabetes mellitus, individuals may present with several different skeletal

TL Dupras, PhD

LJ Williams, PhD

Department of Anthropology, University of

Central Florida, Orlando, USA

H Willems, $\mathrm{PhD}$

C Peeters, MA

\section{ABSTRACT}

The diagnosis of diabetes mellitus from skeletal remains is very difficult given the complexity of the disease and the fact that there are no pathological skeletal characteristics exclusively associated with diabetes mellitus. Skeletal identification of diabetes mellitus may only be possible through differential diagnosis, when several pathological changes are present. Skeletal and dental changes associated with diabetes mellitus include Charcot's joint (neuropathic arthropathy), osteoporosis, osteoarthritis, diffuse idiopathic skeletal hyperostosis (DISH, or Forestier's disease), adhesive capsulitis (frozen shoulder), dental caries, periodontal disease, and antemortem tooth loss.

Skeletal remains of an adult male from the Egyptian archaeological site of Dayr al-Barsha, dated to the Middle Kingdom (ca. 2055-1650 BC), display a myriad of pathological conditions that, when considered together, likely indicate diabetes mellitus, specifically type 2 diabetes mellitus.

This diagnosis represents the earliest, and possibly the only recorded archaeological skeletal evidence for this disease. Copyright $\odot 2010$ John Wiley \& Sons.

Practical Diabetes Int 2010; 27(8): 358-363

\section{KEY WORDS}

diabetes mellitus; type 2 diabetes; diffuse idiopathic skeletal hyperostosis; brachydactyly; osteoporosis; Egypt; Dayr al-Barsha

characteristics, consequently adding to the difficulty of diagnosis.

Skeletal changes associated with diabetes mellitus are not directly caused by the disease itself, and are most often seen as chronic long-term complications associated with types 1 and 2 (early and late onset, respectively). Gestational diabetes, on the other hand, is normally short term (the length of the pregnancy) and usually does not lead to skeletal changes. Skeletal characteristics typically associated with chronic diabetes include adhesive capsulitis (frozen shoulder), diffuse idiopathic skeletal hyperostosis (DISH, or Forestier's disease), Charcot's joint (neuropathic arthropathy) as part of the diabetic foot complex, osteoarthritis, and osteopaenia/osteoporosis. ${ }^{6-10}$ Diabetes mellitus also has a discernable association with dental caries, periodontal disease, and antemortem tooth loss. ${ }^{11-13}$

Subfaculteit Taal- en Regiostudies,

Katholieke Universiteit Leuven, Leuven,

Belgium

*Correspondence to: Dr Tosha Dupras, Department of Anthropology, University of
One individual's skeletal remains from the site of Dayr al-Barsha, Egypt, display a myriad of pathological characteristics that, when considered together, present a strong case for the diagnosis of diabetes mellitus, and may represent the earliest and only published skeletally identified archaeological case of diabetes mellitus.

\section{Skeletal/dental characteristics of diabetes mellitus Adhesive capsulitis}

Adhesive capsulitis is an idiopathic condition whose aetiology is not clearly understood; however, it has been reported as having a significant correlation with diabetes mellitus, particularly type $2 .^{6,14}$ The disease appears to have a high prevalence in individuals over 40 years of age and is associated with the duration of diabetes. ${ }^{14}$ Although the disease itself is primarily found in the soft tissues of

Central Florida, Orlando, FL 32816, USA; e-mail: tdupras@mail.ucf.edu

Received: 18 June 2010

Accepted in revised form: 10 August 2010 
the shoulder, clinical radiographs commonly show associated bony responses such as osteoporosis, degenerative arthritic changes, and osteophytic development in the scapular glenoid cavity and the humeral head. ${ }^{15}$

\section{Diffuse idiopathic skeletal hyperostosis}

Diffuse idiopathic skeletal hyperostosis is a pathological condition characterised by ossification of the anterior longitudinal ligament and ossifications of other extra-spinal ligaments and entheses. Ossification of the anterior longitudinal ligament is mainly reported on the right side, and DISH is only diagnosed archaeologically if there is contiguous fusion of four or more vertebrae. ${ }^{16}$ Even though it is mainly observed in the thoracic segment of the vertebral column, DISH can occur in any area of the spine. Although the aetiology of DISH is not yet understood, it appears to occur more frequently in individuals with type 2 diabetes, particularly those over 50 years of age. ${ }^{7}$

\section{Charcot's joint (neuropathic arthropathy)}

The feet of individuals with diabetes mellitus can be afflicted with various pathological conditions secondary to peripheral vascular disease, and/or peripheral neuropathy. Poor management of diabetes can lead to peripheral neuropathy, resulting in sympathetic nerve damage and sensory loss in the foot. Neuropathic foot ulcers may develop causing ischaemic osteolysis mainly involving the distal metatarsals and proximal phalanges. ${ }^{16}$ Remodelling of the metatarsals and phalanges often changes the distal ends so that they form a distinctive tapered end (also called diabetic osteopathy), often described as 'pencil-shaped'. ${ }^{17}$ Charcot's joint, or a neuropathic joint, may also result and can lead to progressive changes, such as fracture, osteolysis, fragmentation, new bone formation, subluxation, and, finally, complete joint disorganisation. $^{8}$

\section{Osteoarthritis}

Although osteoarthritis has been associated with type 2 diabetes, diabetes itself is not a risk factor

Table 1. Milestones in the history of diabetes mellitus

\begin{tabular}{|c|c|}
\hline Date & Event \\
\hline $1530 \mathrm{BC}$ & Ebers Papyrus, Egypt - first mention of polyuria \\
\hline $100 \mathrm{AD}$ & $\begin{array}{l}\text { Aretaeus of Cappadocia - first accurate description of the } \\
\text { disease, and coined the term 'diabetes' (from the Greek } \\
\text { 'diabainein') }\end{array}$ \\
\hline $\begin{array}{l}1000 \mathrm{BC} \text { to } 6 \text { th } \\
\text { century } \mathrm{AD} \text { (date } \\
\text { of occurrence } \\
\text { under debate) }\end{array}$ & Susruta of India - first clinical diagnosis of diabetes \\
\hline $1300 s \mathrm{AD}$ & $\begin{array}{l}\text { Purgatives, and astringents prescribed by physicians to } \\
\text { relieve intense polyuria }\end{array}$ \\
\hline $1675 \mathrm{AD}$ & $\begin{array}{l}\text { Thomas Willis - added the word 'mellitus' (from the Latin of } \\
\text { honey) to refer to the sweet taste of urine }\end{array}$ \\
\hline $1776 \mathrm{AD}$ & $\begin{array}{l}\text { Matthew Dobson - confirmed that sugar was present in } \\
\text { both the urine and blood of diabetic individuals }\end{array}$ \\
\hline $1788 \mathrm{AD}$ & $\begin{array}{l}\text { Thomas Cawley - discovered correlation between } \\
\text { shrivelled pancreas and diabetic individuals }\end{array}$ \\
\hline $\begin{array}{l}\text { Early 18th } \\
\text { century AD }\end{array}$ & $\begin{array}{l}\text { Claude Bernard - hypothesised that glycogen was stored } \\
\text { by the liver and secreted as a sugary substance into the } \\
\text { blood. Overproduction of glucose was considered to be } \\
\text { the cause of diabetes }\end{array}$ \\
\hline 1889 AD & $\begin{array}{l}\text { Joseph von Mering and Oscar Minkowski - discovered that } \\
\text { the removal of a pancreas from a dog led to diabetes }\end{array}$ \\
\hline $1893 \mathrm{AD}$ & $\begin{array}{l}\text { Gustave-Edouard Laguesse - suggested that pancreatic } \\
\text { islet cells were involved in diabetes, and named them the } \\
\text { Islets of Langerhans }\end{array}$ \\
\hline $1894 \mathrm{AD}$ & $\begin{array}{l}\text { Moses Barron - linked damaged Islets of Langerhans to } \\
\text { the cause of diabetes, and surmised that the substance } \\
\text { from these cells was the treatment for diabetes }\end{array}$ \\
\hline $1910 \mathrm{AD}$ & $\begin{array}{l}\text { Edward Albert Sharpey-Schafer and Jean de Meyer - } \\
\text { named the substance insulin }\end{array}$ \\
\hline 1923 AD & $\begin{array}{l}\text { Frederick Banting and John Macleod - win Nobel Prize for the } \\
\text { discovery of insulin and production of insulin injections }\end{array}$ \\
\hline $1936 \mathrm{AD}$ & $\begin{array}{l}\text { Harold Percival Himsworth - makes the distinction } \\
\text { between type } 1 \text { and type } 2 \text { diabetes }\end{array}$ \\
\hline $1977 \mathrm{AD}$ & Herbert Boyer genetically engineered synthetic human insulin \\
\hline
\end{tabular}

for osteoarthritis. ${ }^{9}$ Osteoarthritis is more likely associated with obesity, which is a risk factor for type 2 diabetes. Individuals with both type 2 diabetes and obesity show an increase in both small and large joint osteoarthritis. ${ }^{9}$

\section{Osteopaenia/osteoporosis}

Significant bone loss in both the axial and appendicular skeleton has been identified in individuals with type 1 diabetes, although results are contradictory regarding type 2 diabetes with some studies reporting 
Original Article

Pathological skeletal remains from ancient Egypt: the earliest case of diabetes mellitus?

Figure 1. Location of Dayr al-Barsha in Egypt. Inset shows archaeological site divided into excavation zones, with Zone 9A circled

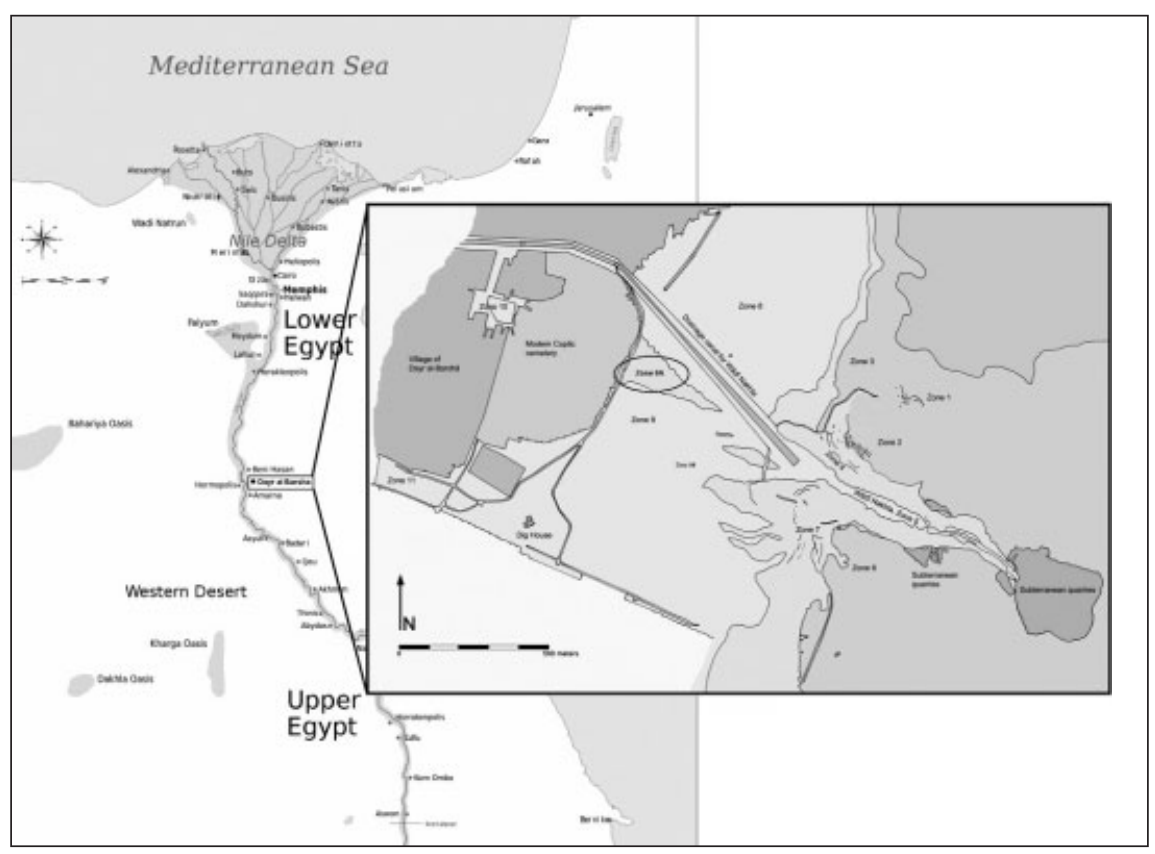

comparatively higher bone mass density, particularly in those with associated DISH. ${ }^{10,18}$ Lower bone mass density places these individuals at higher risk for fractures, particularly of the femoral neck. Osteopaenia and osteoporosis can result from many of the symptoms of diabetes. Polyuria, disruption of the absorption of calcium by the lower intestine, parathyroid secretion problems, and alteration of vitamin D regulation impact on the individual's ability to build and remodel bone. ${ }^{10}$ Because type 1 diabetes commences at a young age, individuals are at a disadvantage for building the bone stores they will need during adulthood, placing them at risk for developing osteoporosis as adults. While those suffering from chronic type 2 diabetes may experience bone loss due to the same symptoms, they start bone loss later in life, and therefore the loss may be less than in those afflicted with type 1 diabetes.

\section{Dental disease}

When uncontrolled, the oral complications of diabetes can be multiple and may include gingivitis and periodontitis, oral candidiasis, xerostomia and salivary gland dysfunction, caries, periapical abscesses, and antemortem tooth loss. ${ }^{12,19,20}$ Of these, periodontal disease, increased dental caries, periapical abscesses and antemortem tooth loss can be diagnosed on skeletal remains. The most common oral complication of diabetes is periodontal disease. ${ }^{12,20}$ Increased serum fructosamine and glycosylated haemoglobin (HbAlc) levels in individuals who do not manage their diabetes have been correlated with When uncontrolled, gingivitis can progress into periodontal disease ultimately resulting in alveolar bone loss. Although the literature is unclear as to whether a change in microflora contributes to the increased incidence and severity of periodontal disease, the oral environment created by unmanaged diabetes appears to indicate this possibility. ${ }^{12,19,20}$ Increased levels of serum calcium in saliva, resulting in calculus, as well as increased glucose levels in gingival crevicular fluid and urea concentrations can promote an environment that alters the oral microflora. ${ }^{12,19}$ Degenerative vascular changes affecting other parts of the body also affect gingival tissues, interfering with the delivery of nutrients and leukocytes and resulting in decreased oxygen and elimination of metabolic waste. ${ }^{19}$ This condition may increase the severity of periodontitis and also affect the ability to heal wounds. Non-enzymatic glycosylation, also a the development of gingivitis. ${ }^{19,21}$ noted complication of unmanaged diabetes, may affect gingival collagen turnover and osteoclast/osteoblast cellular function, resulting in osteopaenia and decreasing the ability to maintain and remodel alveolar bone. ${ }^{12,22}$ Imbalances in lipid metabolism, altered collagen metabolism, neutrophil dysfunction, and altered monocytic response are also associated conditions that increase the likelihood of diabetic individuals developing periodontitis. ${ }^{12,19}$ Although all of the conditions listed previously may act in an additive fashion or work synergistically to affect the development of periodontal disease in the diabetic individual, it is clear that poor metabolic management and duration of the hyperglycaemic state are the two risk factors highly correlated with periodontitis.

Poor metabolic control and elevated glucose levels can cause oral bacteria to multiply at an increased rate, leading to greater rates of caries. ${ }^{12,20}$ Root surface caries are reported to be more prevalent than coronal caries in patients with type 2 diabetes, ${ }^{11}$ likely due to higher levels of chronic and severe periodontal disease. Gingival recession in association with periodontal disease, vascular changes, changes in oral microflora, and abnormal collagen metabolism are all associated with increased root caries in diabetic patients. ${ }^{11}$

Periapical abscesses are also a recognised oral complication of diabetes mellitus and result from bacteria entering the tooth and migrating through the apical foramen into the bone surrounding the root tip. ${ }^{23}$ Microbiological studies have identified a trend toward increased apical symptoms that may be related to the presence of more virulent microorganisms in necrotic pulp of those with diabetes, as, on average, the number of different microorganisms detected is higher in diabetic vs non-diabetic patients. ${ }^{24}$ Fusobacterium, Prevotella, Bacteroides, Peptostreptococcus, Porphyromonas, and Streptococcus are the predominant genera that have been isolated; ${ }^{24,25}$ however, chronic periapical infections in diabetes are more frequently associated with specific anaerobes, particularly Fusobacterium nucleatum, Porphyromonas endodontalis and Porphyromonas gingivalis. ${ }^{24,25}$ 
Figure 2. Lateral view of scapulae showing comparative arthritic changes and osteophyte development on the left glenoid cavity surface

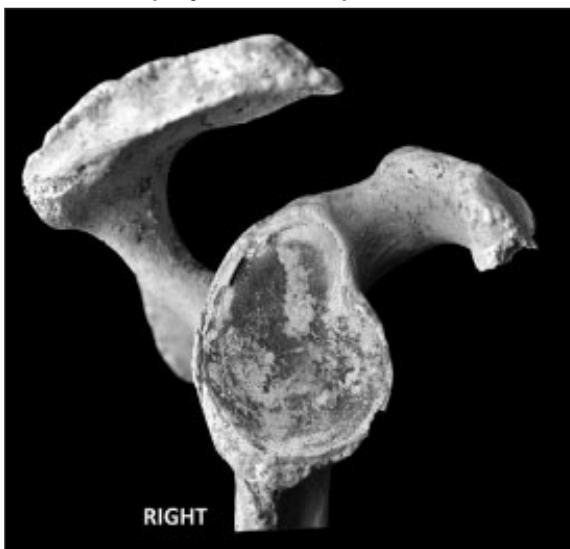

Increased antemortem tooth loss is a common problem in diabetic individuals. Multiple symptoms can cause tooth loss, including increased collagenase and hyperglycaemia. Individuals with diabetes may have an increase in the enzyme collagenase, and when activated it may lead to the loss of connective tissue attachment. $^{12}$ Hyperglycaemia may also reduce the growth of fibroblast, an element essential in building collagen for the periodontium. ${ }^{12}$ The loss of fibroblast growth and increased production of collagenase affect the homeostasis of the periodontal tissues, causing loose teeth and eventually tooth loss. Severe periodontal disease, with or without periapical abscesses, can also destroy alveolar bone and the alveolus, eventually breaking down the periodontal ligament and causing tooth loss. The single-rooted anterior teeth are more likely to be affected first, as they have less surface attachment to alveolar bone than multi-rooted posterior teeth.

\section{Findings and results}

The archaeological site of Dayr alBarsha, Egypt, is located approximately $270 \mathrm{~km}$ south of Cairo on the east bank of the Nile $\left(27^{\circ} 45^{\prime}\right.$ North; $30^{\circ} 54^{\prime}$ East) (Figure 1). The archaeological site is divided into 11 research zones (Figure 1, inset). In 2003 an individual with pathological characteristics suggestive of diabetes mellitus was excavated from Tomb 10O22/1B Feature 277 in Zone 9A. The tombs in this cemetery, arranged in walled complexes, range from large well-built vaulted mud

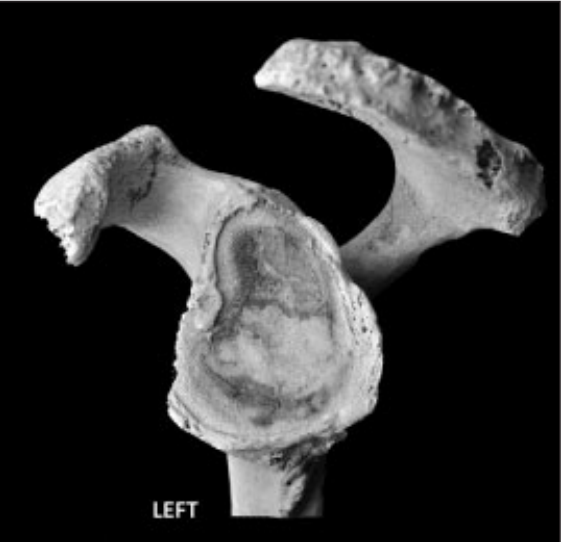

brick tombs to shallow pit tombs with lesser quality funerary equipment. All burials in this zone have been dated to the late First Intermediate Period (ca. 2160-2055 BC) to early Middle Kingdom (ca. 2055-1650 $\mathrm{BC}$ ), with some reuse during the transition from the Second Intermediate Period (ca. 1650-1550 BC) to the New Kingdom (ca. 1550-1069 BC). ${ }^{26-29}$

Tomb 10O22/1 consists of a rectangular shaft $(2.59 \mathrm{~m} \times 1.05 \mathrm{~m}, 4.75 \mathrm{~m}$ deep) at the bottom of which a burial chamber (10022/1B) opens to the north. ${ }^{26,29}$ The entrance to the burial chamber was blocked by a thin wall of sun-dried clay bricks and coarse sand. Grave artifacts include metal model woodworking implements and weapons, pieces of alabaster, the rotted, dusty remains of the bottom of a wooden coffin, some painted plaster remains of a burial mask, and a small collection of ceramics. The ceramic assemblage consists of simple bowls, locally produced bottles, plates and possibly some body shards of drop shaped jars, all dated to the early Middle Kingdom. ${ }^{26-29}$ In antiquity, looters had taken the ceramic vessels out of the dark burial chamber and smashed them in the sunlight of the shaft to search for any valuables they may have contained. ${ }^{27,28} \mathrm{~A}$ small offering consisting of the four legs of a young calf was also recovered. ${ }^{27,28}$ Although the burial in Tomb 10022/1B Feature 277 was looted during antiquity, physical evidence of a secondary burial within the shaft, dating to ca. 1550 BC, suggests that the burial chamber had not been entered after that date,
Figure 3. Diffuse idiopathic skeletal hyperostosis (DISH) showing fusion of thoracic vertebrae 6 through to 11 [left], and lumbar vertebrae 1 through to 3 [right]

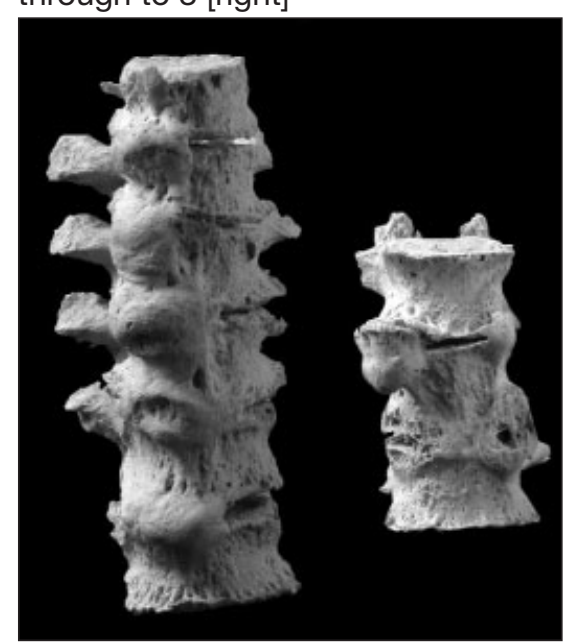

leaving the skeleton of the tomb owner almost complete and well preserved.27,28 Given the position of the tomb in the cemetery and the remains of the burial equipment, the burial in Tomb 10022/1B Feature 277 tentatively dates between ca. 2055 and 1911 BC. ${ }^{27-29}$

The skeletal remains represent an adult male, aged 40-45 years, approximately $170 \mathrm{~cm}$ in height. The individual's pathological conditions are many, including: arthritic and degenerative changes to the surface of the glenoid cavity of the left scapula (Figure 2); fusion of the sixth through to eleventh thoracic vertebrae and first through to third lumbar vertebrae (Figure 3); healed bilateral metatarsophalangeal amputations, with fusions of the left medial cuneiform and first metatarsal, and the right third and fourth metatarsals (Figure 4). The bones of the foot are also very light, indicative of osteopaenia/osteoporosis. In addition, this individual also displayed significant asymmetrical brachydactyly of the right metacarpals (Figure 5).

The individual also exhibits severe dental disease (Figure 6), including heavy wear, advanced periodontal disease, and significant calculus build-up on the lingual side of the mandibular and maxillary teeth. There are also numerous mandibular dental caries, including the right distal surface of the first molar, the buccal side of the right third molar, 
Figure 4. Bilateral metatarsophalangeal amputations, with fusion of the left medial cuneiform and first metatarsal [arrow], and the right third and fourth metatarsals [right]

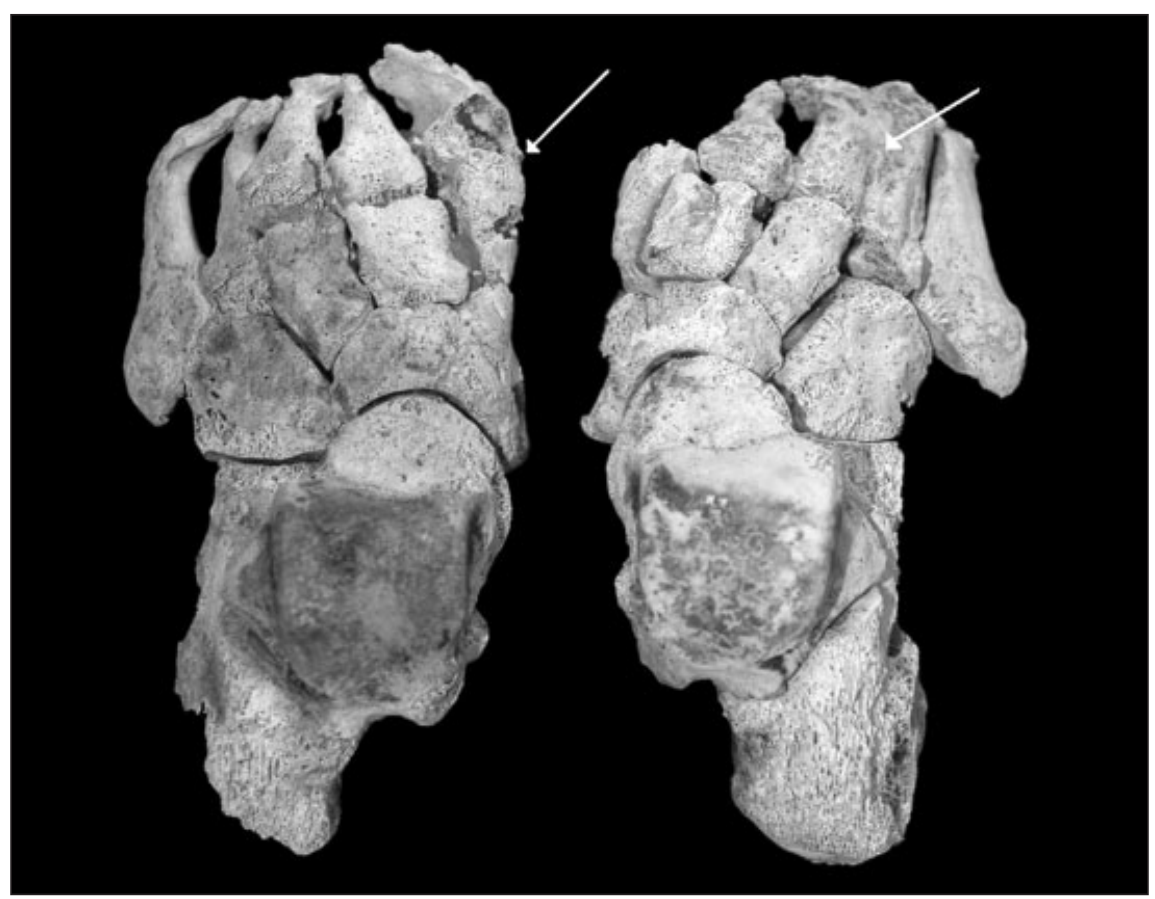

Figure 5. Asymmetrical brachydactyly shown in the dorsal view of the right hand [top, right], and side by side comparison of the right and left metacarpals [bottom], shown from left to right, MC1, MC2, MC3, MC4 and MC5
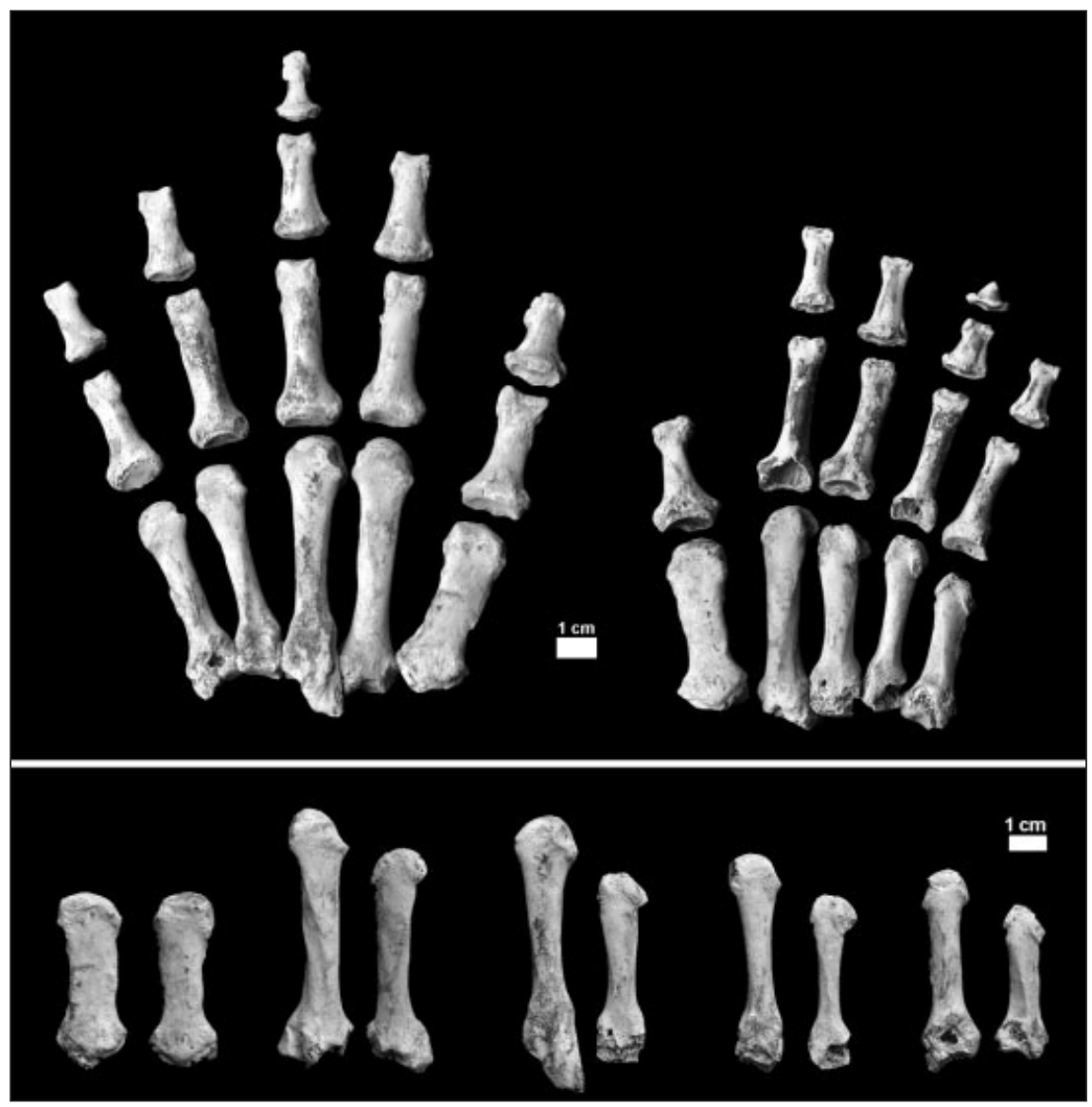

the distal surface of the left first molar, and the mesial and distal surface of the left second molar. All caries are located at the cementoenamel junction (Figure 7). Maxillary antemortem tooth loss (Figure 8) includes the right and left first incisors, the left second incisor, the left first and second premolars, and the right and left second and third molars. Mandibular antemortem tooth loss includes the right and left second incisors, and the left first and second premolars.

\section{Discussion}

When comparing the classic secondary skeletal and dental effects of diabetes mellitus with those found in the remains from Dayr al-Barsha, it is clear that this individual was most likely afflicted with diabetes mellitus. Although it cannot be diagnosed with certainty, the arthritic changes to the surface of the left glenoid cavity may have been the result of adhesive capsulitis. Interestingly, the right scapula remained unaffected, showing unilateral affliction as is common in diabetic individuals. ${ }^{6,14}$ Contiguous right side fusion of the sixth through to eleventh thoracic vertebrae and first through to third lumbar vertebrae is strongly suggestive of DISH. ${ }^{16}$ Even more telling is the condition of this individual's feet (Figure 4). Bilateral amputations at the metatarsophalangeal joints and the tapering of the distal ends of the remaining metatarsals are indicative of diabetic foot complications. The particular healing pattern on the distal ends of the metatarsals (i.e. lateral-to-medial curvature) may result from foot wrapping or prosthetic use. ${ }^{30}$ Although advanced leprosy can cause similar bony responses in the feet, ${ }^{16}$ this individual does not display any other characteristics of leprosy. While the majority of the skeleton does not appear to be osteoporotic, the foot bones are especially light with little cortical bone, indicative of osteopaenia, likely resulting from neuropathic arthropathy. One of the more curious pathologies is the asymmetrical brachydactyly of the right metacarpals. This condition appears to be either genetic or developmental $^{31}$ and most likely does not have a direct relationship with 
Figure 6. Skull of individual showing severe periodontal disease, antemortem tooth loss, calculus formation, and apical abscesses

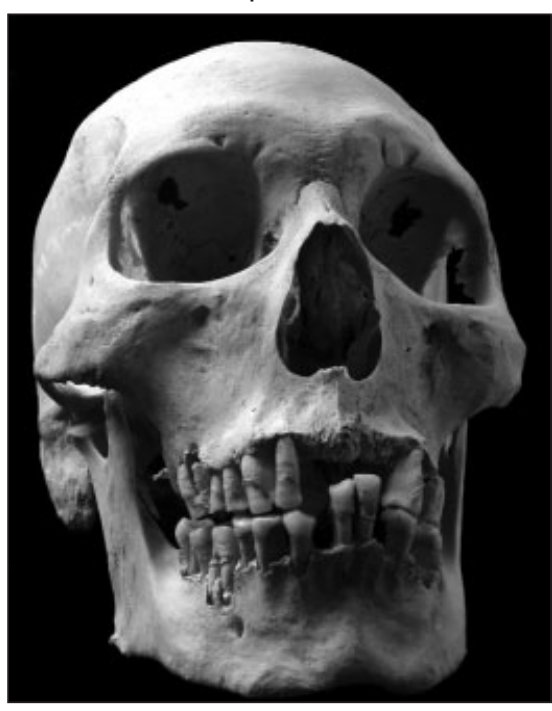

Figure 7. Examples of root caries on the mandibular right third molar [left] and left first molar [right]

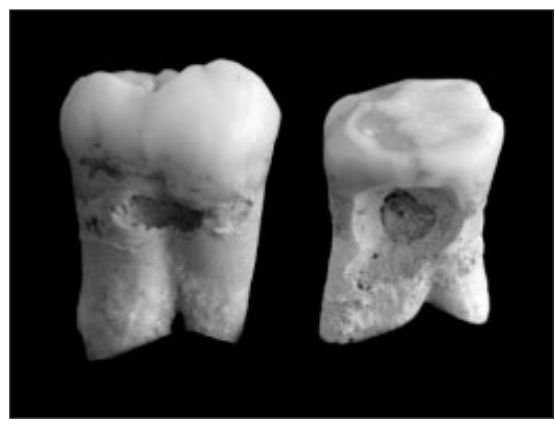

diabetes mellitus; however, brachydactyly and age of onset for type 2 diabetes share regions of linkage on chromosome $12.31,32$

Dental wear due to abrasion, calculus build-up, periapical abscesses and antemortem tooth loss are regularly observed in this archaeological population; nevertheless, the extreme periodontal disease and root caries shown on this individual are unusual, particularly for his age at death. Root caries are observed in high frequencies in individuals with uncontrolled diabetes ${ }^{11}$ and are usually connected to severe periodontal disease and the exposure of the root surface. Severe periodontal disease has also led to the antemortem loss of 12 teeth, which again is unusual for an individual of his age in this population.

Many of the secondary skeletal complications of diabetes are found

Figure 8. Maxillary [left] and mandibular [right] dentition showing advanced dental wear, antemortem tooth loss, and pulp chamber exposure

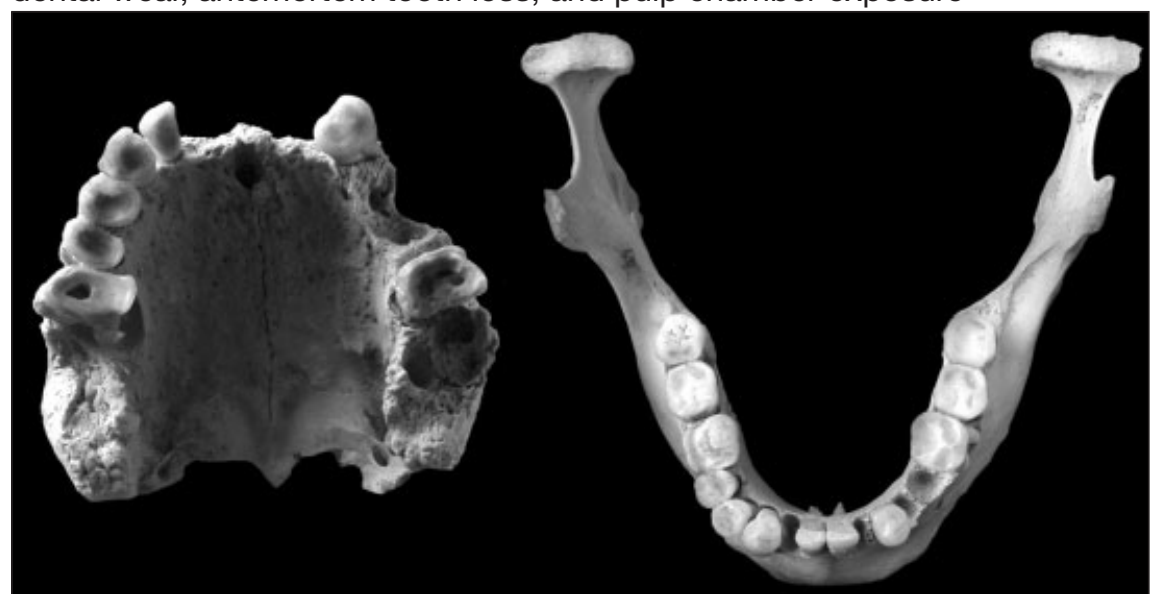

in both type 1 and type 2, but some are more frequently associated with one over the other. While adhesive capsulitis, DISH, and root caries are more prevalent in individuals who have type 2 diabetes, given the age at death and time period of this individual it is most likely that he suffered from type 2 diabetes. There is little reported evidence in the anthropological literature concerning ancient skeletal diagnoses of diabetes mellitus. Those that do mention diabetes as a potential diagnosis do so only in the presence of DISH, and point to the likely association between obesity, DISH and diabetes. ${ }^{33,34}$

\section{Conclusions}

Diabetes mellitus is a disease primarily affecting soft tissue structures. Skeletal changes can appear in individuals who are chronic sufferers of diabetes mellitus, but these symptoms are secondary to the disease. There are no pathological skeletal characteristics exclusive to diabetes mellitus; therefore, a diagnosis of diabetes mellitus from skeletal remains is very difficult. One individual's skeletal remains from the archaeological site of Dayr al-Barsha, present a myriad of pathological characteristics that, when considered together, fit most of the secondary skeletal symptoms expressed in chronic sufferers of type 2 diabetes. At present, the only way to trace this disease is through ancient written sources. This Middle Kingdom period skeleton, dated to 2050-1911 $\mathrm{BC}$, may represent the earliest skeletal evidence of diabetes mellitus.
The fact that this individual lived for a significant period of time with all of these pathological conditions speaks of a society in which care for the sick and disabled was available, and also indicates that this individual may have had wealth and higher status allowing access to this level of care.

\section{Acknowledgements}

The authors would like to thank all members of the Dayr al-Barsha expedition. Particular thanks go to the Egyptian Supreme Council of Antiquities for continued support of this expedition. This research was funded by the Katholieke Universiteit Leuven and the Research Foundation, Flanders.

\section{Conflict of interest statement}

There are no conflicts of interest.

\section{References}

References are available at www. practicaldiabetesinternational.com.

Key points
- Diagnosis of diabetes mellitus
from skeletal remains is a difficult
endeavour
- Skeletal remains from
Dayr al-Barsha, Egypt (dated to
ca. 2050-1911BC) provide
corroborative evidence for the
presence of type 2 diabetes
- This is the oldest and possibly the
only conclusive skeletal evidence
for diabetes mellitus in the
archaeological record




\section{References}

1. Loriaux LD. Diabetes and the Ebers Papyrus 1552 BC. Endocrinologist 2006; 16: $55-6$.

2. King KM, Rubin G. A history of diabetes: from antiquity to discovering insulin. Br J Nurs 2003; 12: 1091-5.

3. Nunn JF. Ancient Egyptian Medicine. Norman: University of Oklahoma Press, 1996; 91-2.

4. Grapow H. Die medizinischen Texte in hieroglyphischer Umschreibung autographiert. Berlin: Akademie-Verlag, 1958; 234-9.

5. Westendorf W. Handbuch der altagyptis chen Medizin. Leiden: Brill, 1999; 597-9.

6. Arkkila PE, et al. Shoulder capsulitis in type I and II diabetic patients: association with diabetic complications and related diseases. Ann Rheum Dis 1996 ; 55: 907-14.

7. Sencan D, et al. The prevalence of diffuse idiopathic skeletal hyperostosis in patients with diabetes mellitus. Rheumatol Int 2005, 25: 518-21.

8. Eyes BE, MacFarlane IA. Radiology of Diabetes. Lancaster: MTP Press, 1986; 56-67.

9. Kim RP, et al. Musculoskeletal complications of diabetes mellitus. Clin Diabetes 2001; 19: 132-35.

10. Carnevale V, et al. Skeletal involvement in patients with diabetes mellitus. Diabetes Metab Res Rev 2004; 20: 196-204.

11. Hintao J, et al. Root surface and coronal caries in adults with type 2 diabetes mellitus. Community Dent Oral Epidemiol 2007; 35: 302-9.

12. Ryan ME, et al. The influence of diabetes on the periodontal tissues. $\mathrm{J} \mathrm{Am}$ Dent Assoc 2003; 134: 34S-40S.

13. Collin HL, et al. Oral symptoms and signs in elderly patients with type 2 diabetes mellitus: a focus on diabetic neuropathy. Oral Surg Oral Med Oral Pathol Oral Radiol Endod 2000; 90: 299-305.

14. Balci N, et al. Shoulder adhesive capsulitis and shoulder range of motion in type II diabetes mellitus: association with diabetic complications. J Diabetes Complications 1999; 13: 135-40.

15. Vencovský J, Broulík P. The endocrine system. In Oxford Textbook of Rheumatology, 3rd edn. Isenberg DA, et al. (eds). Oxford: Oxford University Press, 2004; 185-92.

16. Aufderheide AC, Rodriquez CR. The Cambridge Encyclopedia of Human Paleopathology. Cambridge: Cambridge University Press, 1998; 341-4.

17. Copland WA. Bone changes in diabetes. Proc R Soc Med 1954; 47: 345-7.

18. Sahin G, et al. Study of axial bone mineral density in postmenopausal women with diffuse idiopathic skeletal hyperostosis related to type 2 diabetes. J Womens Health (Larchmt) 2002; 11: 801-4.

19. Ponte E, et al. Diabetes mellitus and oral disease. Acta Diabetol 2001; 38: 57-62.

20. Vernillo AT. Dental considerations for the treatment of patients with diabetes mellitus. J Am Dent Assoc 2003; 134: 24S-33S.

21. Unal T, et al. Fructosamine as a possible monitoring parameter in noninsulin dependent diabetes mellitus patients with periodontal disease. $J$ Periodontol 1993; 64: 191-4.

22. Roe T, et al. Vertebral bone density in insulin-dependent diabetic children. Metabolism 1991; 40: 967-71.

23. Meng HX. Periodontal abscess. Ann Periodontol 1999; 4: 79-82.

24. Foaud AF. Diabetes mellitus as a modulating factor of endodontic infections. J Dent Educ 2003; 67: 459-67.
25. Mandell RL, et al. Microbiology of healthy and diseased periodontal sites in poorly controlled insulin dependent diabetics. I Periodontol 1992; 63: 274-9.

26. Peeters C. Excavations in Zone 9 (Western Island). Preliminary report of the 2002 campaign of the Belgian Mission to Deir al-Barsha. MDAIK 2004; 60: 266-9.

27. Peeters C. Work in Zone 9. Preliminary report of the 2003 campaign of the Belgian Mission to Deir al-Barsha. MDAIK 2006; 62: 328-37.

28. Peeters C. Excavations in the Western Cemeteries at Deir al-Barsha: results and perspectives. In Proceedings of the Ninth International Congress of Egyptologists, Grenoble, 6-12 September 2004. Goyon JC, Cardin C (eds). Leuven: Uitgeverij Peeters, 2007; 1481-83.

29. Willems $\mathrm{H}$, et al. Preliminary report of the 2004-2005 Campaigns of the Belgian Mission to Dayr al-Barsha. MDAIK 2008; 64: in press.

30. Dupras TL, et al. Evidence of amputation as medical treatment in ancient Egypt. Int J Osteoarchaeol 2010; 20: 405-23.

31. Luft FC. Mendelian forms of hypertension and mechanisms of disease. Clin Med Res 2003; 1: 291-300.

32. Wiltshire $\mathrm{S}$, et al. Evidence from a large UK family collection that genes influencing age of onset of type 2 diabetes map to chromosome $12 \mathrm{p}$ and to the MODY3/ NIDDM2 locus on 12q24. Diabetes 2004; 53: 855-60.

33. Rogers J, Waldron T. DISH and the Monastic way of life. Int J Osteoarchaeol 2001; 11: 357-65.

34. Verlaan JJ, et al. Diffuse idiopathic skeletal hyperostosis in ancient clergymen. Eur Spine J 2007; 16: 1129-35. 